\title{
Cortical blindness and the functions of the non-geniculate fibres of the optic tracts
}

\author{
G. S. BRINDLEY, P. C. GAUTIER-SMITH, AND W. LEWIN \\ From the Department of Physiology, Institute of Psychiatry, London, the National Hospital, \\ Queen Square, London, and the Department of Neurological Surgery and Neurology, \\ United Cambridge Hospitals
}

Of the fibres of the human or simian optic tract, the majority run to the lateral geniculate nucleus. This nucleus has other inputs besides the optic tract, but has probably only one output, the geniculo-calcarine tract (Poljak and Hayashi, 1936).

A substantial minority of the fibres of the optic tract, 20 to $30 \%$ in man according to Bernheimer (1899), go to other destinations. The largest groups of such non-geniculate fibres end in the superior colliculi and pretectal region, but Pasik and Pasik (1968) have given evidence that those that end in the nucleus paralemniscalis (accessory optic system) may be important visually. At least in the rat (Sefton, 1968), many optic nerve fibres divide and send one branch to the lateral geniculate nucleus and one to the superior colliculus. The present paper will consider what may be the function of non-geniculate fibres. The only function that is already established beyond doubt for them is to regulate the size of the pupil; the light reflex of the pupil requires those fibres that go to the pretectal region but not those that go to the superior colliculus (Magoun and Ranson, 1935). Other functions have been proposed on the basis of animal experiments, but have not been validated for man. The noteworthy suggestions are:

1. a visual function essentially similar to that of the geniculo-calcarine system but cruder in its discriminations (Marquis, 1934);

2. maintenance of a stationary optical image on the retina by means of reflex eye movement (ter Braak, 1936);

3. provision of visual feedback for cerebellar co-ordination of learned skilled movements(Brindley, 1964);

4. a collaboration with the geniculo-calcarine system in higher visual functions, whereby these suffer rather similar severe disorders (not total loss) when either the geniculo-calcarine or the collicular system is lost (Sprague, 1966, modified and clarified by Schneider, 1969, who emphasizes the special involvement of the collicular system in visually directed orientational movements).
If the first or fourth of these suggestions be correct, blindness from injury to the human occipital cortex should never be complete and lasting. Klüver (1942), Pasik, Pasik, and Krieger (1959), Weiskrantz (1963), and Humphrey and Weiskrantz (1967) found it to be very incomplete in monkeys.

If the second suggestion were correct, we might expect optokinetic nystagmus to persist, at least in part, after destruction of the occipital poles of the hemispheres. In cats and dogs it does so (ter Braak, 1936; Smith, 1937), and in monkeys it may perhaps do so, but the evidence is conflicting (ter Braak, 1936, ter Braak and Vliet, 1963-in favour; Pasik et al., 1959, and Pasik and Pasik, 1964-against).

If the third suggestion were correct, we might expect that cortically blind patients would in some circumstances perform habitual tasks better in light than in darkness, even though they were unaware of seeing in the light.

Cases of apparently complete cortical blindness are scarce in the literature. In the large series of occipital war wounds described by Inouye (1909), Marie and Chatelin (1915), Holmes and Lister (1916), Poppelreuter (1917), Holmes (1918), Symonds (1945), Spalding (1952), and Teuber, Battersby, and Bender (1960), and among the nine cases of bilateral infarction of the occipital lobes described by Symonds and Mackenzie (1957), no patient was ever found, when examined by the physician, to be unable to distinguish light from darkness, though several gave histories of having been totally blind for some hours or days. The only published cases that we can find where inability to distinguish light from darkness was found on examination, though the pupils reacted normally to light, are that of Bouveret (1887), the case described on p. 635 of Rossolimo (1896), case 2 of Lunz (1897), case 2 of Anton (1899), that of Saenger (1919), case 4 of Monbrun and Gautrand (1920), the two cases of Hemphill (1941), that of Yaskin and Spaeth (1945), cases 4 and 6 of Redlich and Dorsey (1945), that of Velzeboer (1952), and, apparently, every one of the 
12 cases of Bergman (1957). With all 24 published cases (and perhaps especially with the more recent of them) there is room for a little scepticism on the ground that the authors assumed that the reality of total cortical blindness was already established, and do not seem to have been much concerned with testing received opinion about it.

On optokinetic nystagmus in cortical blindness, published information is even scarcer. Velzeboer (1952) found it absent in her patient. Bergman (1957) directly states that it was absent in two of his patients, and there is a general statement at the top of his p. 576 which may mean that he found it to be absent in the others. Teuber et al. $(1960$, p. 50) refer to one patient, who after two cerebral vascular accidents complained of total blindness, in whom no optokinetic nystagmus could be elicited, though the pupils reacted to light. We can find no other published case where an attempt to elicit optokinetic nystagmus is mentioned.

\section{OBSERVATIONS}

Two patients will be described, both of whom could when examined make no visual discriminations except that between suddenly illuminating a dark room and suddenly darkening a brightly lit one, though their pupils reacted well to light. Any description of such a patient ought to answer the following questions:

1. what visual discriminations were attempted without success?

2. was the performance of the patient in tests of non-visual discrimination good? For if not, the failure in visual tasks might not be significant;

3 . is there good collateral evidence that the occipital lobes were damaged, and that the nongeniculate fibres of the optic tract were intact?

\section{CASE 1}

This patient, aged 47 (Addenbrooke's Hospital No. 211933) was admitted to hospital on 26 November 1965 under the care of one of us (W.L.) for further treatment of a meningo-sarcoma of the parieto-occipital region involving the bone and the sagittal sinus. There had been three previous operations between 1962 and 1965 to remove the tumour short of sacrificing the sagittal sinus. The visual acuity until 1965 was excellent, but during that year the vision fluctuated with attacks of nearly complete blindness in January and March, and transient improvements after partial excisions of the tumour in March and July. On 12 October 1965 the patient could still read words in Jaeger (J) 4 with the left eye and J.8 with the right. His surviving visual field at that time was confined to the right upper quadrants.

On admission there was doubtful perception of light in either eye which was judged to be completely lost $\bar{Z}$ pre-operatively 10 days later. He was correctly orientated $\Phi$ in space and time, made good conversation, and did not search for words, although as far as could be tested there was a suspicion of mild dysphasia. There was a posterior $\underset{0}{0}$ vault decompression with the thickening of the overlying 0 soft tissues. The eye movements were full and the pupillary reactions equal and brisk. There was a slight $\stackrel{\bigcirc}{\mathcal{S}}$ degree of bilateral secondary optic atrophy, which had been present since an episode of papilloedema in 1962 before the first operation. The knee and ankle jerks were very brisk with bilateral ankle clonus. Position sense was mildly impaired in all four limbs.

On 8 December a large mass of tumour was removed. The superior sagittal sinus was found to be occluded $\overline{\bar{\omega}}$ and the involved segment removed. During this operation $\frac{\vec{\sigma}}{\vec{\partial}}$ the occipital lobes were stimulated electrically. The $\varrho$ results-hardly relevant to the present paper-are is described elsewhere (Brindley and Lewin, 1968).

On 15 December (G.S.B.) his speech was slow, but ? there was no evident dysarthria or dysphasia. In sensory $\overrightarrow{\vec{H}}$ testing he responded accurately except that he had some ${ }_{\sigma}$ astereognosis: he was quite unable to recognize a threepenny piece with either hand, but correctly identified a cigarette lighter with the right hand and a paint brush $\dot{\omega}$ with the left. He said that he had no idea whether the $N$ room in which he was examined (which could be, and was from time to time, totally darkened) was dark of ज light; and when pressed to give an opinion he answere at random. However, when he was warned that a swit亩 would be turned which would lighten the room if $\frac{1}{11}-$ was dark or darken it if it was light, he always correctly distinguished the sudden darkening from the sudde lightening, and said that he did this by seeing a diffuses of light or darkness in front of him.

On 17 December (G.S.B.) he was still unable distinguish steady light from steady darkness, and still. able to distinguish sudden darkening from sudden 0 lightening. If in an otherwise dark room a strong light was flashed directly at his face, he could tell that it was flashing (and said that he did this by seeing) but had no idea of its direction. If the light was covered with either $\frac{}{\not}$ red or blue celluloid he could not distinguish between $\propto$ the two colours. If the light, instead of being flashed, $\overrightarrow{\vec{O}}$ was waved in front of his face either vertically or hori- 3 zontally he sometimes reported it as flashing, but never $\bar{D}$ had any idea that it was moving, or, if he were told that it was moving, of the direction of its movement. When a large internally illuminated drum painted on the inside $\overline{5}$ with alternate black and white stripes each subtending? $10^{\circ}$ at the axis was placed around his head and rotated ${ }^{\circ}$ (so that almost the whole of both retinal images moved coherently) he had no idea of the direction of the rotation $\delta$ of the drum, and no optokinetic nystagmus could be detected, either by inspection of his eyes or by electro- 0 oculography. Eye movements to command were normal, and the pupils reacted briskly to light.

By 17 January 1966 he could count fingers at $2 \mathrm{~m}$. To do so, he had to direct his eyes a little to their left. $N$ Perimetry on 12 January with a $1^{\circ}$ white test object showed a right homonymous upper quadrant of vision $\mathbb{N}$ extending to $35^{\circ}$; he could see nothing in any other $\underset{\omega}{\mathcal{N}}$ 
quadrant. His visual acuity on that day was $6 / 9$ with either eye, though it took him a long time to find each letter in order to read it. In the revolving striped drum he recognized easily the direction of movement, and optokinetic nystagmus in both directions was obvious (though not quite normal), both by inspection of the eyes and by electro-oculography.

The patient died elsewhere in August 1966, and no necropsy was done.

\section{CASE 2}

Mrs. P (National Hospital No. A33715), a widow aged 70, was admitted to Worthing Hospital on 31 October 1966, under the care of Dr. J. F. P. Skimshire, having been found unconscious at home. She had had complete heart block, with occasional Stokes Adams attacks, since 1962. In the three weeks after admission to hospital, her level of consciousness gradually improved, although she remained confused and disorientated. On 21 November, it became evident that she was blind and at the suggestion of Dr. John Foley, she was transferred to the National Hospital, Queen Square, under the care of one of us (P.C.G.S.).

When admitted to the National Hospital on 6 December, she denied that she was blind, saying only 'my eyesight isn't very good'. Her pulse rate was 36 per minute and blood pressure $230 / 60 \mathrm{mmHg}$ and there was a harsh aortic systolic murmur. She was disorientated as to time and place, and had a mild nominal dysphasia. She was able to repeat five digits backwards and on the W.A.I.S. a verbal IQ of 102 was obtained, but her memory for recent and past events was hopeless. She was unable to retain new information for more than 45 seconds. Bilateral astereognosis was present and both plantar responses were extensor but, otherwise, neurological examination was negative; in particular the eye movements were normal and the pupillary reactions to light, although rather sluggish, were present. Optokinetic nystagmus was absent to all directions and speeds of the drum. A clinical diagnosis of infarction of both occipital lobes was made and confirmatory evidence was provided by the finding of a dense symmetrical occipital uptake of isotope on ${ }^{197} \mathrm{Hg}$ scan (Fig. 1). Electroencephalography showed a generalized decrease in electrical activity in both occipital regions, and no evoked responses were present on photic stimulation. An aortic arch angiogram showed evidence of atheroma in the lumina of the right carotid and vertebral arteries, but the basilar and both posterior cerebral arteries were shown to fill.

When examined by G.S.B. on 23 December 1966, she was able to carry on a trivial conversation competently and grammatically, with occasional circumlocutions when she failed to find the right word. She still denied that she was blind, but admitted that her sight was poor. She was co-operative and quick in routine sensory testing, and, except for vision, accurate within the limits of her nominal dysphasia. Thus she correctly identified a half-crown with either hand; when a pair of spectacles was put in her right hand she said 'for seeing', and when a brush was put in her left hand she said 'for brushing hair'. She could consistently distinguish sudden darkening of a lighted room from sudden lightening of a dark one, and said that she did it by seeing. Dr. A. M. Halliday tested this independently with more stringent precautions against auditory clues, with the same result. In all other tests of visual function her answers were completely random. In particular, she could not distinguish light from darkness unless the transition from one state to
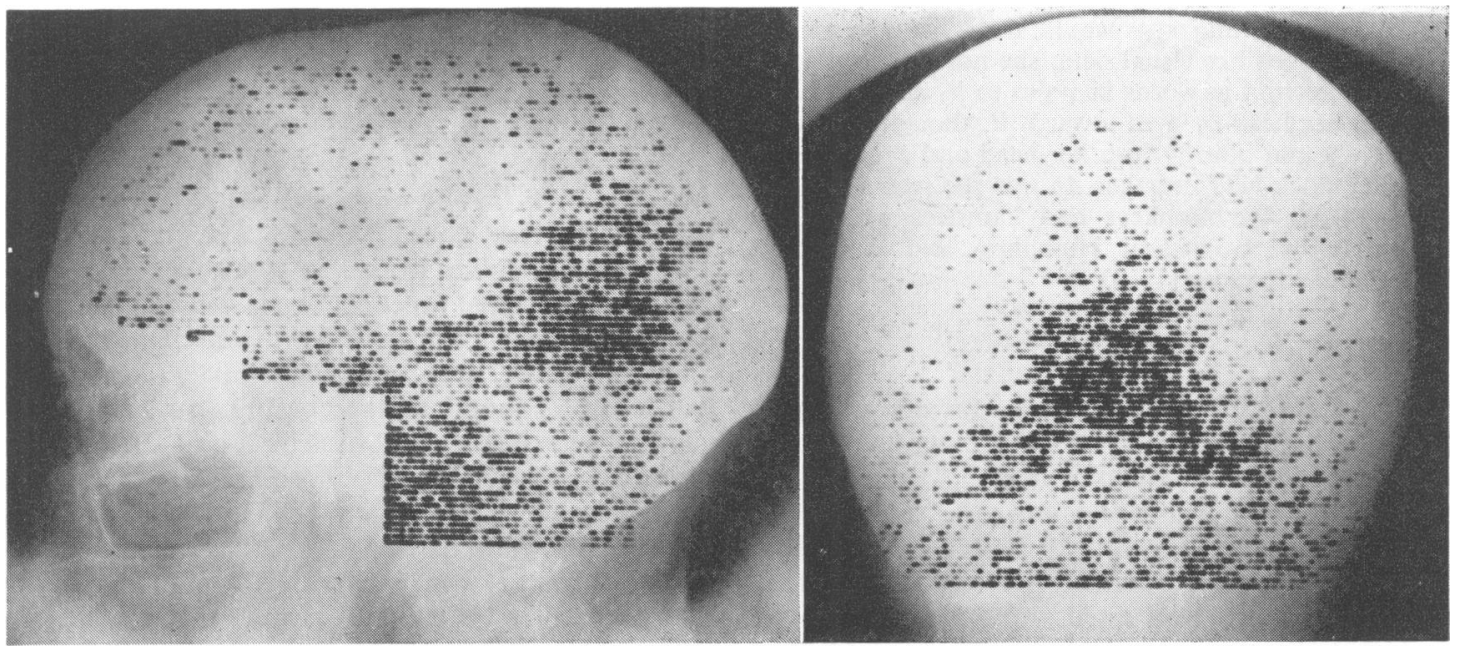

FIG. 1. ${ }^{197} \mathrm{Hg}$ chlormerodrin brain scan, showing an extensive bilateral area of abnormal isotope uptake in the occipital region. 
the other was sudden and occurred while she was attending to it. She could not identify the direction of a light, its colour (red or blue), or whether it was moving. If told that a light was being waved in front of her either up and down or from side to side, she could not distinguish between the two directions of movement.

The patient was discharged from the National Hospital on 6 January 1967. She was seen again by P.C.G.S. on 15 March 1967, when her clinical state was unchanged, but a repeat of the ${ }^{197} \mathrm{Hg}$ scan showed that the area of increased isotope uptake in the occipital region had decreased considerably.

Mrs. P. was seen again by G.S.B. on 7 January 1969. Her complete heart block was still present, and she had had further Stokes Adams attacks. She was still disorientated as to time and place, and her memory had not improved, but her trivial social conversation was remarkably good, considering her lack of memory. In conversation, no dysphasia was detectable, but when asked to name objects placed in her hands she sometimes responded with a circumlocution first, and gave the name only after a short pause. Her vision was unchanged since two years before, except that she no longer denied her almost total blindness. She still confidently and correctly distinguished sudden darkening of a brightly lit room from sudden lightening of a dark one, but failed to distinguish light from darkness when the transition had been gradual, failed to identify the direction or colour of a bright light held in front of her face, and failed to distinguish vertical from horizontal movement of a light. In the revolving striped drum, she could not identify the direction of movement, or tell whether the drum was moving or stationary. There was no optokinetic nystagmus. Her eye movements to command were normal, and her pupils reacted well to light. She was seen again on 8 May 1969, when all the tests performed on 7 January were repeated with the same results. It was further noted that, when a light was silently flashed within what would, if she had had normal sight, have been her visual field, she not only could not state its direction in words or point to it, but also could not turn her head or eyes towards it, though she could confidently and quickly turn her head and eyes towards a ticking clock held near her. In this she seems to differ sharply from the monkeys and hamsters with visual cortical lesions studied by Humphrey and Weiskrantz (1967) and Schneider (1969).

\section{DISCUSSION}

In both these patients the evidence for the intactness of the non-geniculate fibres of the optic tracts is good; the pupillary reactions prove that those to the pretectal region survived, and the normal eye movements to command make it very probable that those to the superior colliculi were intact, for they could have been interrupted without injury to any oculomotor mechanism only by very circumscribed bilateral lesions. There is no reason to suspect any hysterical component in either patient's disorder, and both were good enough witnesses in other sensory tests for their visual responses (though not what Mrs. P, when first seen, said about her visuai capacities) to be trusted. In both there was firm evidence for a lesion affecting both occipital lobes, in case 1 from the appearance at craniotomy and in case 2 from the ${ }^{197} \mathrm{Hg}$ scan and the results of electroencephalography.

What these patients prove is that cortical blindness can be at least as complete as theirs was (reported above). They do not prove that it cannot be absolute, for the residual capacity that they both had to distinguish sudden light from sudden darkness may have been due to a residue of surviving visual cortex. Case 2, in which the cortical blindness has already lasted more than two years, suggests that when the occipital lobes are permanently destroyed the blindness remains permanently complete or nearly so. The restoration of vision in case 1 does not contradict this conclusion, for it was doubtless due to returning function in the left occipital lobe, probably from improvement in its blood supply.

The absence of optokinetic nystagmus is clear, as is its return in case 1 when some visual cortical function returned and its failure to return in case 2,0 where there was no indication of returning visuad $\mathrm{N}$ cortical function. Ter Braak's suggestion that non geniculate fibres maintain a stationary image on the retina by means of reflex eye movements gains ne support, for man, from these clinical observations.

Natural selection can hardly permit a large system of fibres and cells to exist in the brain if they are of no use, and the one known function of nonf은 geniculate fibres (the light reflex of the pupil) requires only those that run to the pretectal region. For the rest, chiefly collicular, the four suggested functions listed in the introduction to this paper are the only ones that have any plausibility; to deny all four is to leave little chance of making sense of the visual pathways. Each has some experimental evidence in its favour, and they are not incompatible, so that all four could be true. The first-that is, that non-geniculate fibres, whatever else they may do, permit a visual function that is essentially similar to that of the geniculo-calcarine system-has especially strong support from animal experiments; yet it runs counter to the common supposition of clinical neurologists that destruction of the occipital lobes causes lasting total blindness. The observations of the present paper confirm and extend the common clinical supposition; they show that cortical blindness can be very nearly total for at least two and a half years. The greatest durations that we can discover previously reported are four months (case 2 of Anton, 1899), five months (case 3 of Bergman, 1957), five and a half months (case 4 of Monbrun and Gautrand, 1920), and 29 months interrupted by 
two episodes of slight return of vision (Saenger, 1919). The conflict of our second case, and Saenger's case, with the published observations on monkeys seems sharp; for example, Weiskrantz (1963) found in a $4 \frac{1}{2}$-month-old rhesus monkey the first indication of returning visual function on the 11 th day after ablation of both occipital lobes, and complex visual tasks accurately performed within eight weeks. The difference may be one of species, or may perhaps depend on the sparing, in the experiments on monkeys, of some part of the geniculo-cortical projection area, or the involvement, in our case 2 , of some region of cortex that is essential for the functioning of the non-geniculate visual pathways. Whatever its cause, it can be reconciled only with some artificiality with the supposition that the function suggested by Marquis (1934) or that suggested by Sprague (1966) for the non-geniculate fibres is valid for man.

There remains the third of the four suggestions listed in the introduction, the provision of visual feedback for the cerebellar co-ordination of learned skilled movements. In an attempt to test this, we have watched our patients performing habitual actions, in the course of which they presumably formerly used visual information. The aim was to assess whether, when cortically blind, they performed these actions better than one would expect of a sighted person with his eyes shut. They never did so. Our second patient was also carefully observed when eating with her eyes open and with her eyes closed. No difference could be detected in the manner in which she ate.

Our observations raise difficulties for all the suggested functions of non-geniculate optic tract fibres that we have listed, but in no case absolutely insuperable difficulties. We regret our inability to assign a function to these fibres, but think that we have succeeded in putting on much firmer ground a group of facts that any theory of their function must account for.

\section{SUMMARY}

Two cases of blindness due to lesions restricted to the posterior parts of the cerebral hemispheres are described. Both patients could distinguish sudden illumination of a dark room from sudden darkening of a light one, but failed completely in all other tests of visual function, including the discrimination of steady light from steady darkness. One had, at first, anosognosia for the disorder, the other never did. Both lacked optokinetic nystagmus. In one of the cases the almost total cortical blindness has already lasted over two and a half years.
The relation of these observations to the effects of cortical lesions in monkeys, and to published hypotheses as to the functions of the non-geniculate fibres of the optic tracts, is discussed.

We wish to thank Dr. J. R. Braybrooks, of Thames Ditton, who has looked after the second patient, Mrs. P., since she left hospital, for his great help and co-operation.

\section{REFERENCES}

Anton, G. (1899). Úber die Selbstwahrnehmung der Herderkrankungen des Gehirns durch den Kranken bei Rindenblindheit und Rindentaubheit. Arch. Psychiat. Nervenkr., 32, 86-127.

Bergman, P. S. (1957). Cerebral blindness: an analysis of twelve cases, with especial reference to the electroencephalogram and patterns of recovery. Arch. Neurol. Psychiat. (Chic.), 78, 568-584.

Bernheimer, S. (1899). Die Wurzelgebiete der Augennerven, ihre Verbindungen und ihr Anschluss an die Gehirnrinde, Pp. 1-115 in Handbuch der gesamten Augenheilkunde, Vol. 1, Part 2. Edited by A. G. Graefe and T. S. Saemisch. Springer: Berlin.

Bouveret, L. (1887). Observation de cécité totale par lésion corticale; ramollissement de la face interne des deux lobes occipitaux. Lyon méd., 56, 337-345.

ter Braak, J. W. G. (1936). Untersuchungen über optokinetischen Nystagmus. Arch. néerl. Physiol., 21, 309-376.

mus in the monkey. Psychiat. Neurol. Neurochir. (Amst.), 66, 277-283.

Brindley, G. S. (1964). The use made by the cerebellum of the information that it receives from sense organs. I.B.R.O. Bulletin, 3,80 .

- and Lewin, W. S. (1968). The sensations produced by electrical stimulation of the visual cortex. J. Physiol. (Lond.), 196, 479-493.

Hemphill, R. E. (1941). Sudden blindness of cortical origin as a result of a cerebral vascular lesion. Irish J. med. Sci., 28-31.

Holmes, G. (1918). Disturbances of vision by cerebral lesions. Brit. J. Ophthal., 2, 353-384.

_ lesions, with special reference to the cortical representation of the macula. Brain, 39, 34-73.

Humphrey, N. K., and Weiskrantz, L. (1967). Vision in monkeys after removal of the striate cortex. Nature (Lond.), 215, 595-597.

Inouye, T. (1909). Die Sehstörungen nach Schussverletzungen der kortikalen Sehsphäre, nach Beobachtungen an Verwundeten der letzten japanischen Kriege. Engelmann: Leipzig.

Klüver, H. (1942). Functional significance of the geniculo-striate system. Cold Spr. Harb. Symp. quant. Biol., 7, 253-299

Lunz, M. A. (1897). Zwei Fälle von corticaler und Seelenblindheit. Dtsche. med. Wschr., 23, 610-613.

Magoun, H. W., and Ranson, S. W. (1935). The central path of the light reflex: a study of the effect of lesions. Arch. Ophthal., 13, 791-811.

Marie, P., and Chatelin, C. (1915). Les troubles visuels dus aux lésions des voies optiques intra-cérébrales et de la sphère visuelle corticale dans les blessures du crâne par coup de feu. Rev. Neurol., 22, 882-925.

Marquis, D. G. (1934). Effects of removal of the visual cortex in mammals, with observations on the retention of light discrimination in dogs. Res. Publ. Ass. nerv. ment. Dis., 13, 558-592.

Monbrun, A., and Gautrand, G. (1920). Quatre observations d'hémianopsie double. Arch. Ophtal., 37, 232-238.

Pasik, P., and Pasik, T. (1964). Oculomotor functions in monkeys with lesions of the cerebrum and the superior colliculi, Pp. 40-80 in The Oculomotor System. Edited by M. B. Bender. Harper \& Row: New York.

- , and $-(1968)$. Further studies on extrageniculostriate vision in the monkey. Trans. Amer. neurol. Ass., 93, 262-264.

,-- , and Krieger, H. P. (1959). Effects of cerebral lesions upon optokinetic nystagmus in monkeys. J. Neurophysiol., 22, 297-304.

Poljak, S., and Hayashi, R. (1936). The cerebral representation of the retina in the chimpanzee. Brain, 59, 51-60.

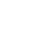


Poppelreuter, W. (1917). Die psychischen Schädigungen durch Kopfschuss im Kriege 1914/17. Band 1: Die Störungen der niederen und höheren Sehleistungen durch Verletzungen des Okzipitalhirns. Voss: Leipzig.

Redlich, F. C., and Dorsey, J. F. (1945). Denial of blindness by patients with cerebral disease. Arch. Neurol. Psychiat. (Chic.), $53,407-417$.

Rossolimo, G. (1896). Ueber Hemianopsie und einseitige Ophthalmoplegie vascularen Ursprungs. Neurol. Z Zl., 15, 626-637.

Saenger, A. (1919). Ein Fall von dauernder zerebraler Erblindung nach Hinterhauptsverletzung. Ibid., 38, 210-211.

Schneider, G. E. (1969). Two visual systems. Science, 163, 895-902.

Sefton, A. J. (1968). The innervation of the lateral geniculate nucleus and anterior colliculus in the rat. Vision Res., 8, 867-881.

Smith, K. U. (1937). The postoperative effects of removal of the striate cortex upon certain unlearned visually controlled reactions in the cat. J. genet. Psychol., 50, 137-156.

Spalding, J. M. K. (1952). Wounds of the visual pathway. II: The striate cortex. J. Neurol. Neurosurg. Psychiat., 15, 169-183.
Sprague, J. M. (1966). Interaction of cortex and superior colliculus in mediation of visual guided behavior in the cat. Science, 153, 1544-1547.

Symonds, C. P. (1945). Visuo-sensory aspects (In discussion on ocular sequelae of head injuries). Trans. ophthal. Soc. U.K., 65, 3-19.

- , and Mackenzie, I. (1957). Bilateral loss of vision from cerebral infarction. Brain, 80, 415-455.

Teuber, H. L., Battersby, W. S., and Bender, M. B. (1960). Visual Field Defects after Penetrating Missile Wounds of the Brain. Harvard University Press: Cambridge, Mass.

Velzeboer, C. M. J. (1952). Bilateral cortical hemianopsia and optokinetic nystagmus. Ophthalmologica (Basel), 123, 187-188.

Weiskrantz, L. (1963). Contour discrimination in a young monkey with striate cortex ablation. Neuropsychologia, 1, 145-164.

Yaskin, J. C., and Spaeth, E. B. (1945). Acute cortical blindness with recovery: report of a case. Arch. Neurol. Psychiat. (Chic.), 54, 70-71. 